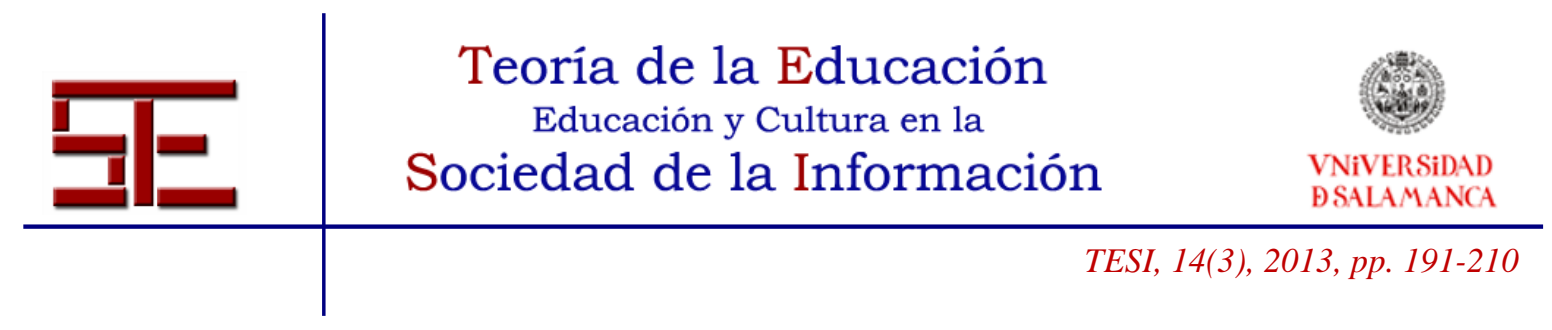

\title{
HACIA OTRA EDUCACIÓN EN LA SOCIEDAD DEL CONOCIMIENTO: CUESTIONES Y PROPUESTAS PEDAGÓGICAS
}

Resumen: Este artículo pretende analizar, en primer lugar, algunas cuestiones centrales implicadas en "la sociedad del conocimiento" y "la educación en la sociedad del conocimiento". Así, el conocimiento es resultado de la actitud de búsqueda de la verdad y rechazo del error. Por otra parte, se destaca el carácter tecnológico y económico de la educación en nuestra sociedad y sus implicaciones educativas. En segundo lugar, se propone educar de otro modo, dentro de una concepción humanista de la educación, en concreto desde la pedagogía de la alteridad. Desde esta orientación, se aportan razones y algunas propuestas concretas de educar en la alteridad: el dinamismo de la donación como contenido moral; un nuevo estilo de relación educativa: la acogida y el diálogo, y, por último, el aprendizaje de la compasión como itinerario educativo de solidaridad y justicia social.

Palabras clave: Sociedad del conocimiento; educación de la alteridad; compasión; relación educativa; acogida; hospitalidad; Lévinas; ética.

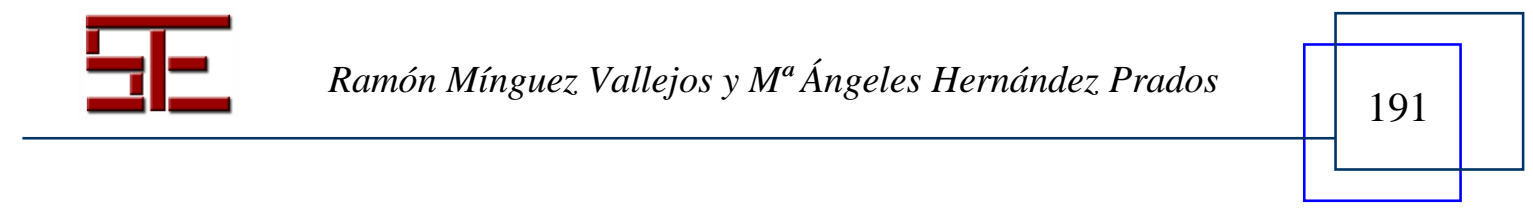




\title{
TOWARDS OTHER EDUCATION ON KNOWLEDGE SOCIETY: PEDAGOG- ICAL ISSUES AND PROPOSALS.
}

\begin{abstract}
This article aims to analyze, firstly, some key issues involved in "knowledge society" and "education in the knowledge society". Thus, knowledge is the result of the attitude of seeking truth and error rejection. On the other hand, highlights the technological and economic character of education in our society and its educational implications. Then, we propose otherwise educate within a humanistic education, specifically from the pedagogy of alterity. From this guidance, provide reasons and some concrete proposals educate otherness: the dynamism of the donation as a moral content, a new style of educational relationship: the reception and dialogue, and finally, learning compassion as educational path of solidarity and social justice.
\end{abstract}

Key words: Knowledge society; education of alterity; compassion; educational relationship; take in, hospitality, Levinas, ethics. 


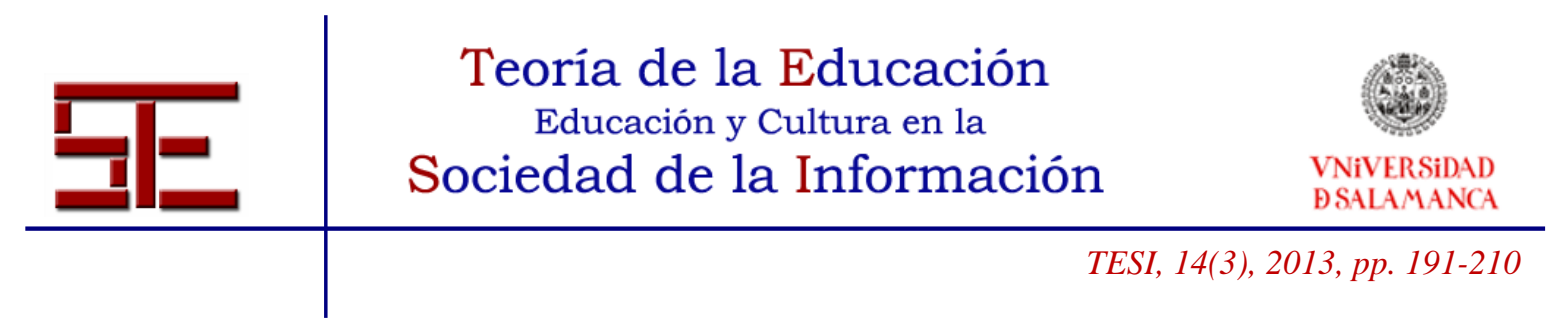

\title{
HACIA OTRA EDUCACIÓN EN LA SOCIEDAD DEL CONOCIMIENTO: CUESTIONES Y PROPUESTAS PEDAGÓGICAS
}

Fecha de recepción: 24/06/2013; fecha de aceptación: 06/09/2013; fecha de publicación: 30/11/2013

\author{
Ramón Mínguez Vallejos \\ rminguez@um.es \\ Universidad de Murcia \\ Mángeles Hernández Prados \\ mangeles@um.es \\ Universidad de Murcia
}

\section{INTRODUCCIÓN}

Este artículo pretende abordar algunos de los problemas centrales de la educación en la sociedad del conocimiento. Si alguna cuestión destaca hoy que afecta directamente a la educación es la ausencia de modelos fundamentales que sean válidos para la vida de las personas y de los grupos. Esta pérdida de orientaciones básicas compartidas produce confusión y perplejidad, inseguridad en los procesos educativos. Ya no son los docentes o las figuras parentales los referentes más decisivos de la formación de las personas, sino otras agencias impersonales con mayor poder de configuración y persuasión.

Por eso, lo que se enseña y aprende por los medios tradicionales no deja de ser algo provisional y fragmentario, porque las nuevas tecnologías de la información y de la comunicación han contribuido a sustituir, e incluso a anular, lo que transmiten familias y escuelas, estableciendo nuevos valores, lenguajes y patrones de comportamiento estrechamente relacionados con intereses económicos y políticos (Carracedo, 2009). Por su parte, las declaraciones oficiales en materia educativa tienden a promulgar una cultura fundamentada en los derechos sociales y civiles, en cambio, la realidad cotidiana apunta en otra dirección: por ejemplo, la lógica de lo popular tiende hacia sentimientos xenófobos y la política educativa se dirige hacia el respeto de los principios democráticos que subyacen en el 'mestizaje cultural'. A nadie puede extrañar, pues, que hoy la educación contemporánea está sometida a un escenario conflictivo en el que, por primera vez, van a ser perdurables las diferencias entre los seres humanos a causa de la ausencia de un modelo universal y válido para todos (Bauman, 2012).

Además, vivimos en una sociedad en donde el conocimiento es fuente de progreso económico y bienestar para muchos. Desde hace algunos años, la expresión sociedad del conocimiento forma parte de nuestro lenguaje, pero no está claro lo que significa e implica en la vida personal y colectiva. Y ello invita a una reflexión más detenida. Es claro que el conocimiento se ha convertido en la piedra angular de la sociedad actual y que, a consecuencia de la enorme circulación de nuevos conocimientos, obliga a actualizar

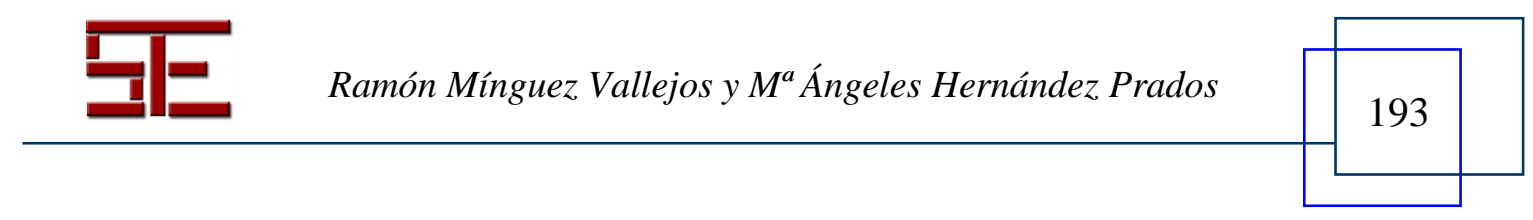




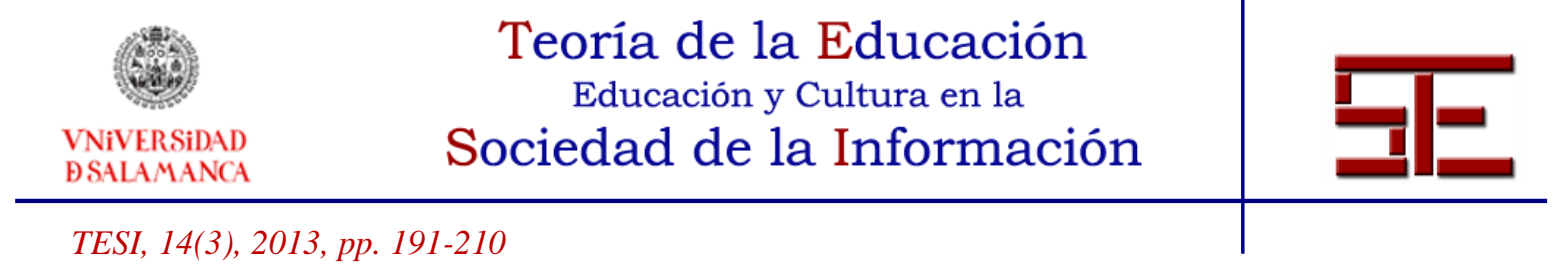

constantemente lo que sabemos y hacemos. Si esta realidad condiciona a que los conocimientos sean aprendidos como útiles y prácticos en la vida cotidiana, también sitúa a las personas en una posición de claro relativismo cognitivo y moral con el riesgo de que afloren otras posiciones negadoras, dogmáticas y excluyentes de cualquier principio moral, norma social o creencia religiosa que otorgue justificación a la vida personal y colectiva.

En nuestra sociedad, por lo general, la escuela y la universidad se han dedicado a enseñar lo que coloquialmente llamamos 'conocimientos útiles'. Pero siendo necesarios e importantes, no lo es todo. Es cierto que tales conocimientos han hecho de la ciencia y la tecnología un ámbito insustituible para la mejora de la vida de las personas y han liberado a la humanidad de muchos problemas contribuyendo con soluciones eficaces, pero no menos cierto es que no pueden ofrecer solución a todos los problemas y perplejidades humanas. La denominada mentalidad tecnológica se ha impuesto como modelo apropiado y casi exclusivo en la formación de los educandos. Y ello encierra una paradoja: se parte del supuesto de que esa educación debe promover personas que impulsen nuevos conocimientos científicos y tecnológicos para el desarrollo en términos económicos; es decir, la educación debe estar comprometida con el crecimiento económico de un país. Sin embargo, crecer económicamente no está correlacionado directamente con la generación de personas que dispongan de mejor calidad de vida (Drèze y Sen, 2002).

Aunque la economía y la tecnología son motores de la sociedad actual, se necesitan de otros elementos que contribuyan a que las personas sean educadas más allá de esos parámetros. Y plantear otra educación se corresponde con el deseo de que la persona no sea reducida a su condición más mercantil, dado que "resulta más fácil tratar a las personas como objetos" (Nussbaum, 2010, 46), fáciles de manipular y, en consecuencia, personas que se olvidan del otro en busca de su propio beneficio. Estamos necesitados, pues, de una educación que se responsabilice del otro, de un modelo educativo en que los conocimientos no sean instrumentalizados, ni tampoco el educando sea tomado como un consumidor de conocimientos en tanto que se preocupe de su propio interés y enclaustrado en una cultura del yo.

Creemos que es una evidencia incontestable que, desde aquí, resulta imposible proponer un gran diseño educativo que haga frente a una educación basada en la rentabilidad, en el beneficio económico. Sin embargo, sí es posible proponer algunas acciones educativas fundadas en otros presupuestos. Por eso, en este texto nos ocuparemos de analizar algunas cuestiones básicas más centradas en el desarrollo humano como nuevo enfoque de la educación en la sociedad del conocimiento. A tal efecto, en lo que sigue intentamos desentrañar el significado del conocimiento que busca la promoción integral del ser humano; de tal clarificación, estaremos en condiciones de comprender cuál es el papel de la educación en la sociedad actual y, a continuación, delimitar algunas propuestas educativas que contribuyan a hacerse cargo del otro.

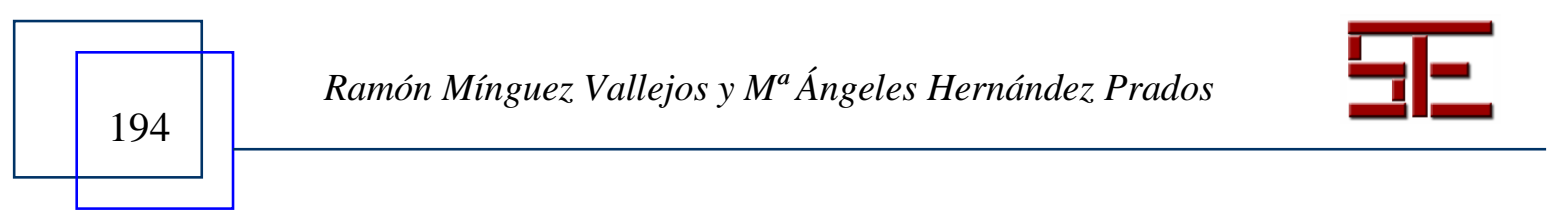




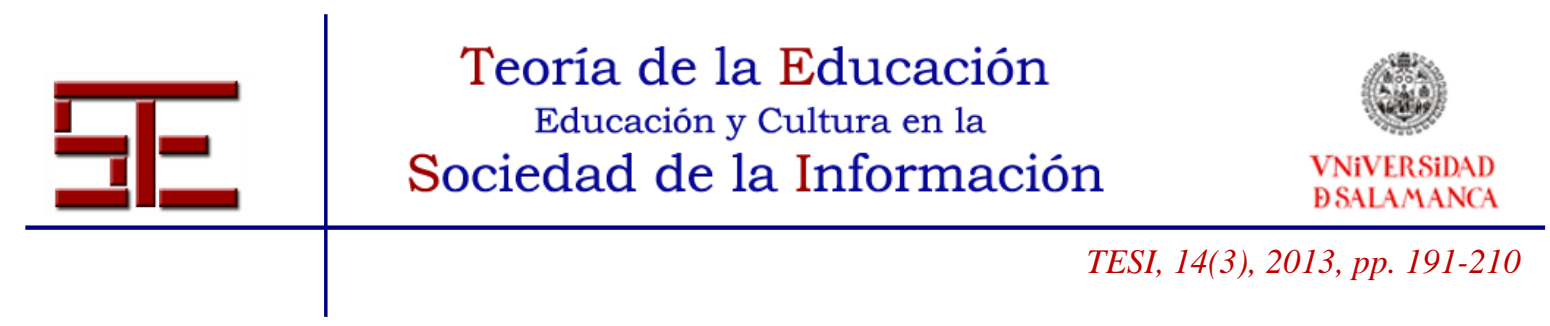

\section{EL CONOCIMIENTO EN LA SOCIEDAD ACTUAL}

Una señal inequívoca de nuestro tiempo es la gran cantidad de información que circula a nuestro alrededor. Nunca como ahora, con el auge de las TIC, las personas han tenido la posibilidad de acceder a una información tan amplia, plural y actualizada. Y ello podría servir como escenario para hacer realidad uno de los sueños de Kant y el movimiento ilustrado: desterrar el oscurantismo y alumbrar al género humano con la luz del conocimiento, sapere aude (Aramayo, 2001). En efecto, delimitar lo que significa el conocimiento en esta sociedad de la sobreabundancia de información sea justamente la divisa del jatrévete a saber!, a pensar por ti mismo, a emitir juicios críticos y a encontrar criterios que sean dignos de seguirlos de modo cabal. Aunque pudiera parecer un deseo al alcance de nuestra mano, sin embargo, hoy se habla tanto de información como de conocimiento como fenómenos indistintos de la sociedad actual.

No resulta fácil separar ambos términos, aunque no son exactamente equivalentes. Mientras que la información alude a un conjunto de datos que están organizados sobre un asunto determinado, siendo transmitida a través de algún medio de comunicación, el conocimiento no es algo que lo tenga un individuo, como si fuera un objeto que se pueda poner delante de nosotros para aprenderlo de modo objetivo. El conocimiento es resultado de una actitud vital: el deseo de conocer lo que es objeto de indagación, discurriendo o con preguntas. Apoyándose en Aristóteles, Dante Alighieri $(1995,51)$ escribió que "todos estamos sujetos al deseo de saber".

Por su parte, conocer no está exento de dificultades en su comprensión. Aquí no adoptamos ninguna posición de crítica psicológica sobre los modos a través de los cuales las personas adquieren conocimiento, ni tampoco posición filosófica alguna que examine todo lo relacionado con la idea de conocer. A nuestro juicio, lejos de restringir aquí lo que sea el conocimiento y cómo se aprende, conocer es un itinerario que recorremos todos y cada uno de nosotros para acercarnos a la verdad. Y dado que la verdad, al menos en nuestra sociedad, se construye según una determinada interpretación histórica dominante, será la misma vida disminuida, desposeída, abatida, la que revelará sus déficits. En la medida en que la vida de las personas sea socavada, reclamará una revisión a fondo de las interpretaciones fundamentales de la verdad en vigor (Gevaert, 2008). Aquella verdad que se haya impuesto por imperativo religioso, político, cultural o científico, ha sido desmoronada a lo largo de la historia como causa del sufrimiento, mal e injusticia que han producido en la vida de las personas.

Con estas premisas, conocer no es sinónimo de saber acceder a la información oportuna y actualizada. Hoy accedemos a un volumen ingente de información y no por ello necesariamente sabemos más y mejor (Martínez y Gutiérrez, 2011). Informar y conocer no coinciden en su significado más genuino, sino que ambas acciones nos sitúa en una perspectiva nueva, en la que no importa tanto la habilidad técnica para el acceso, como la actitud de qué hacemos y para qué utilizamos la información. Desde esa actitud, las

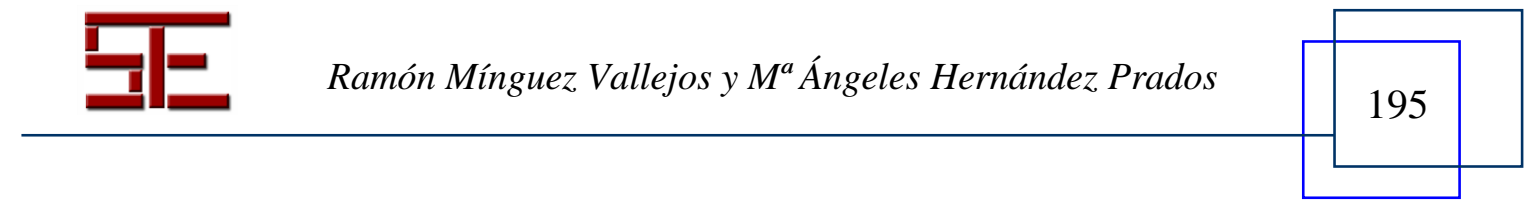




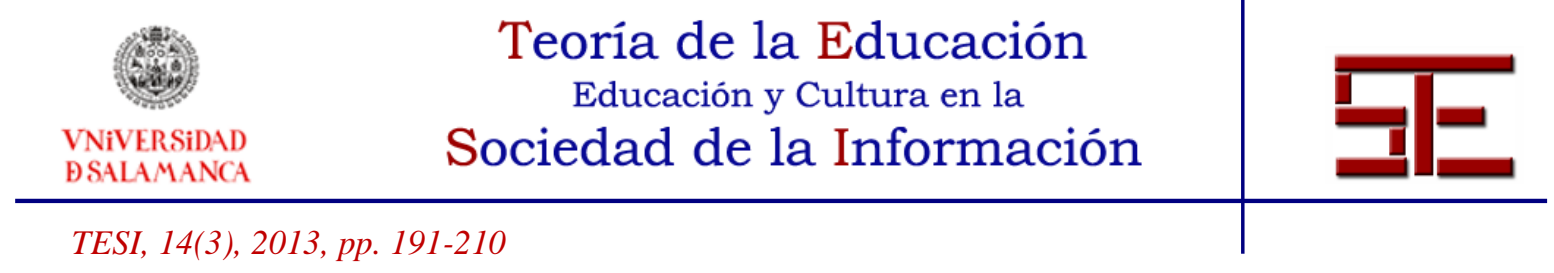

personas deberían adoptar una doble posición: aceptar y rechazar información para discernir lo verdadero de lo falso y ponderar en su justa medida lo que realmente sea relevante para su vida. El deseo de conocer obedece en primer lugar a estar atento a las necesidades de la persona; por lo que el conocimiento no debería estar enfocado solo a disponer de explicaciones sobre el mundo de la naturaleza, sino también a resolver los problemas centrales que impiden el desarrollo de la vida humana y de un orden social justo. De ahí que la búsqueda del conocimiento no debería desvincularse de valores y opciones éticas que sean contrarios a lo justo para cualquier ser humano, por lo que verdad y justicia deberían ir unidas en la sociedad del conocimiento.

Desde esta perspectiva, conocer es buscar lo cierto y rehusar el error; es el empeño a no equivocarse, a encontrar la solución correcta entre varias posibles. Al proceder de ese modo, se asume el carácter vulnerable de la persona. Ello nos recuerda que no poseemos una naturaleza cerrada y terminada, conclusa, sino que somos seres históricos, ubicados en un tiempo y espacio concreto (Chillón, 2010). Bien mirado, equivocarse sería fuente de desarrollo humano. Nuestra limitación humana hace que surjan errores de modo inexorable, pero sería nocivo negarlos o mirar para otro lado. Y eso es precisamente lo que constituye nuestra vida: aprender a ser humano desde que nacemos hasta que morimos (Duch, 2004).

Ser un aprendiz es el que está siempre en disposición de cambiar. Porque no podemos quedarnos encerrados en nuestro conocimiento, aprendemos y discernimos, tomamos partido por esto o por aquello según avanzamos, a sabiendas de que nunca estamos en posesión de todo el conocimiento y de que siempre el error va unido a nuestra vida. Por eso, aprender conocimientos no consiste solo en encontrar las respuestas adecuadas, sino en atender más a las preguntas que las respuestas. Al fin y a la postre, somos buscadores de conocimientos, de saberes que oscilan siempre entre el éxito y el fracaso. $\mathrm{Y}$ en esa ambigüedad nos reconocemos como eternos aprendices.

Por la antropología filosófica sabemos que el hombre no está encerrado en su mundo, del que sólo surgen respuestas y comportamientos fijos. Como ser abierto, su forma de actuar es la de estar ex - puesto a. De ahí que, en vez de conducirse de modo invariable en un ambiente limitado, tiene que esbozar proyectos y realizar o malograr propósitos. Por más que pueda parecer una ficción, la vida es novedad que renueva sus interrogantes y nosotros no disponemos de respuestas prefabricadas con las que podamos contar, sino que probamos respuestas y ponemos en marcha acciones tentativas a los problemas y a situaciones concretas que nos surgen al paso.

Pero la mercantilización del conocimiento ha inducido a estar encerrado en nuestra coraza de individuos que buscan el saber por sí solos. La máxima de alcanza lo que deseas se ha convertido en el criterio más común de esta sociedad consumista y tecnológica. Mientras que la cultura del consumo (Zamora, 2011) nos ha convertido más en consumidores que en productores de conocimiento, lo tecnológico se ha impuesto en nuestra

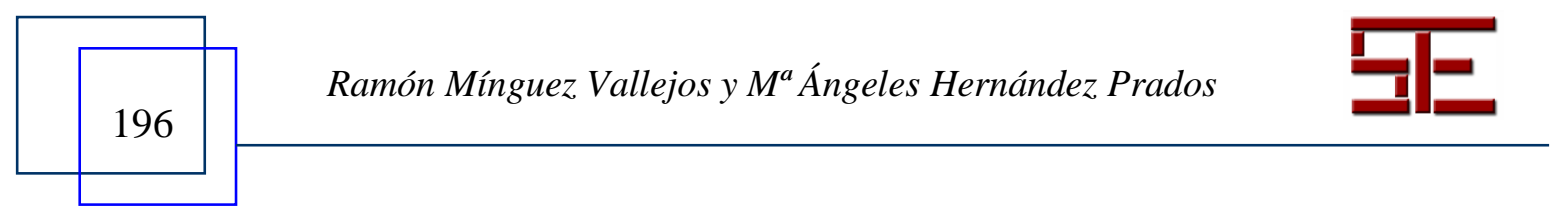




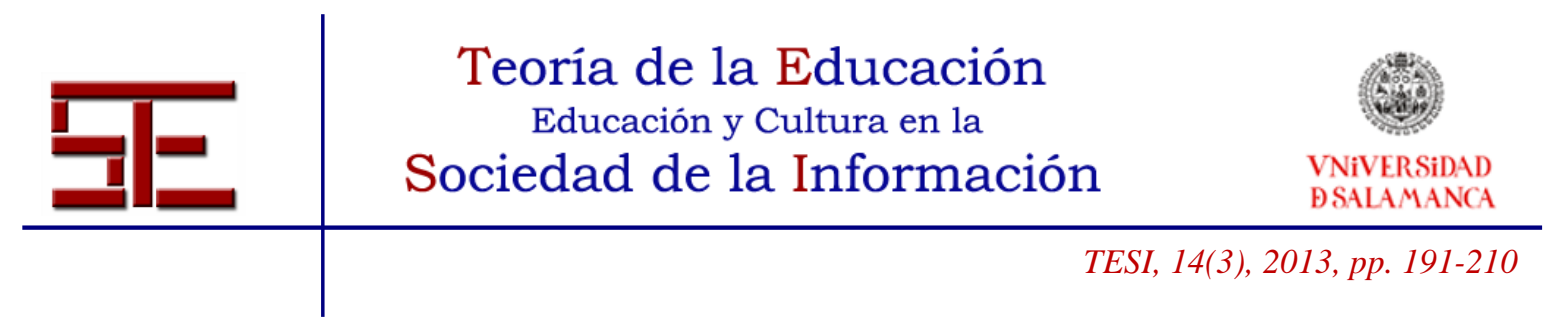

vida de un modo tan invasivo que se anticipa a nuestras preguntas, deseos y motivaciones y nos lanza ya prefabricadas las respuestas.

En el fondo, sólo tiene valor aquel conocimiento que resulta económicamente rentable. Así, la rentabilidad constituye la referencia central y el criterio decisivo para toda clase de actuaciones. Con ello se está produciendo una especie de colonización y sometimiento de las personas, de desidentificación, desculturalización y servilismo. Uno de los hechos más notables de esta sociedad es la sustitución del ciudadano por el de consumidor (Bauman, 2006). El ciudadano tiene como característica distintiva la disponibilidad a la solidaridad con sus conciudadanos y a la participación responsable en los asuntos públicos. En cambio, el consumidor se preocupa de lo que cree que es su interés y se encierra en sus propias vivencias; dirige su mirada a lo "nuevo", a la última novedad que, por otro lado, vive sumergido en un estado de desazón y desesperanza, porque nunca consigue la satisfacción definitiva, porque el afán consumidor convierte al "producto deseado" en "desecho" a causa de la lógica impuesta del usar y tirar. ¿No sería una de las tareas de la educación poner en marcha una "sana pedagogía" que evite producir un sentimiento de ignorancia a causa del impetuoso crecimiento de nuevos conocimientos y no menos rápido envejecimiento de los viejos? ¿No sería de la máxima importancia una educación que prepare la voluntad humana a "salir de sí mismo" y "meterse en la piel del otro", a renunciar a ser el "centro" de su vida y a practicar el des-interés a favor del otro? Dar respuesta a estas cuestiones nos lleva indefectiblemente a replantear lo que significa educar en esta sociedad.

\section{EDUCACIÓN Y SOCIEDAD DEL CONOCIMIENTO}

Resulta harto evidente que nuestras aulas se han nutrido cada vez más de recursos técnicos, de nuevas tecnologías, que han desdibujado el carácter netamente humano de la educación. Con esa realidad y la puesta en marcha de medidas políticas a favor de la incorporación de las TIC en los procesos educativos, se ha extendido una mentalidad tecnológica que ha determinado el aprendizaje escolar, afectando al desempeño docente y a la valoración de los resultados educativos, entre otros aspectos cruciales. Esa mentalidad ha sido presentada como una nueva oportunidad para poner al día a la educación en "condiciones competitivas ventajosas" y que el conocimiento se convierta en un poderoso motor del crecimiento económico.

Cada vez resulta más evidente que las reformas educativas, aplicadas a la escuela y a la universidad, se han vinculado al discurso de la eficiencia y de la rentabilidad. Y ello es consecuencia del nuevo concepto de educación adoptado por la Comisión Europea: la inversión en competencias para lograr mejores resultados socioeconómicos (Comisión Europea, 2012). El motivo que subyace en ese nuevo concepto es la sospecha de que la educación actual no esté suministrando todo lo que el mercado de trabajo necesita en

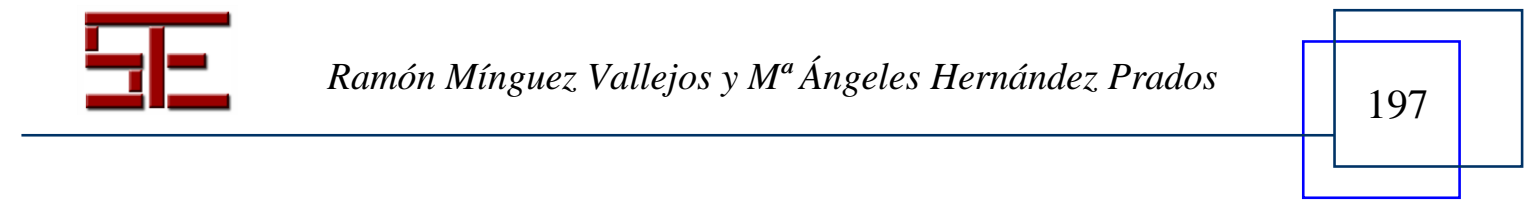




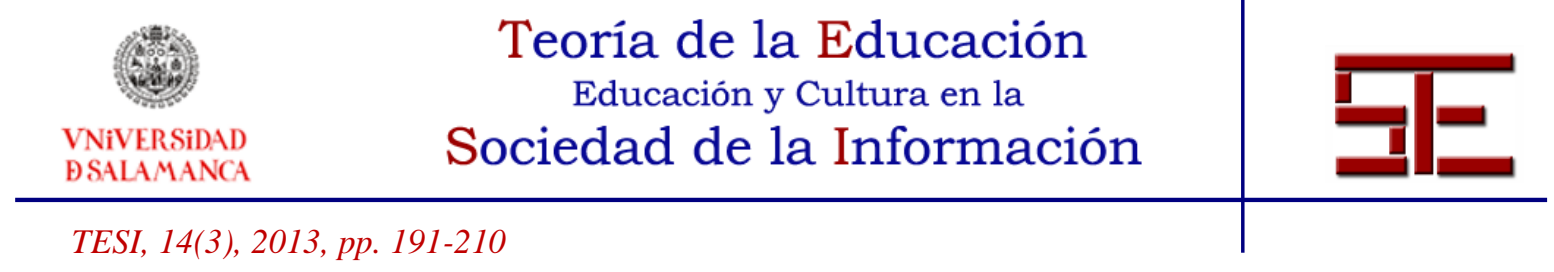

realidad. Se insiste en que "los retos más apremiantes para los Estados miembros son atender las necesidades de la economía y buscar soluciones para atajar la escalada del desempleo juvenil" (Comisión Europea, 2012, 2). Esa insistencia viene avalada, entre otros, por los deficientes resultados educativos que se muestran en informes internacionales como PISA, PIRLS, o TIMSS. Aunque la escuela sigue siendo considerada como una de las instituciones clave, estamos ante una situación donde la educación se ha convertido en una de las preocupaciones más importantes tanto de la opinión pública, como también de las políticas que pretenden dar respuesta a los desafíos futuros que nos lanza el presente (López Rupérez, 2012). En tanto que nuestra mirada es pedagógica, consideramos oportuno desvelar el tipo de educación que predomina en el marco de la sociedad del conocimiento.

No siempre se acierta a descifrar el camino adecuado de lo que se reconoce como educación cuando sólo se orienta dicha tarea desde determinada visión constructivistacognitiva del aprendizaje. Esta visión ha sido ampliamente admitida en la sociedad del conocimiento como el paradigma desde el cual permite incardinar los procesos de enseñanza-aprendizaje en un marco explicativo coherente (Pozo, 2005). Dicho marco determina la tendencia orientadora de esos procesos educativos en la obtención de tres competencias básicas (Eurydice, 2002; Jonnaert, 2002; Comisión Europea 2004, 2007): cognitiva para el análisis de la información y los significados que construye el educando; afectivo-relacional que analiza el sentido personal de lo que aprende el educando (disposición y motivación) e instruccional para la obtención de las competencias necesarias de un aprendizaje autorregulado y estratégico (Gargallo, 2012).

Esta visión concibe al ser humano en términos básicamente de agente activo que procesa la información y parte del presupuesto de que la mente humana es un sistema complejo que opera con símbolos, de modo que los datos introducidos en la mente de los educandos actúa como si fuera un sistema de procesamiento de la información, en donde se codifica y se almacena para recuperar parte de ella con posterioridad. Elementos claves en esta visión constructivista son: a) la organización de la información, en tanto que el sujeto debe realizar internamente un proceso de relacionar la nueva información con la preexistente; b) la significatividad de la información, es el propio sujeto quien orienta su propio aprendizaje, y c) se concede un lugar prioritario a la memoria como núcleo básico de la elaboración de la información y de la actividad humana.

Con estos enunciados tan sólo estamos señalando un problema que afecta directamente a la teoría y praxis pedagógica en la sociedad del conocimiento y el uso de las nuevas tecnologías como escenarios de aprendizaje. Aquí hemos optado por centrar nuestra atención en el supuesto valor irrepetible de cada ser humano: "Si el hombre no es superior a la máquina, ¿Lo será axiológicamente?” (Ruiz de la Peña 1994, 109). Si la respuesta es negativa, sería fácil rechazar la posibilidad de educar personas libres, responsables y con capacidad de juicio crítico. En el fondo, una educación que pone su énfasis

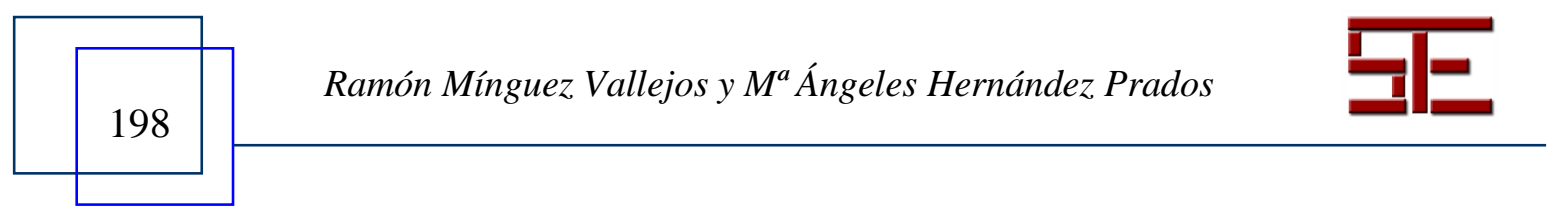




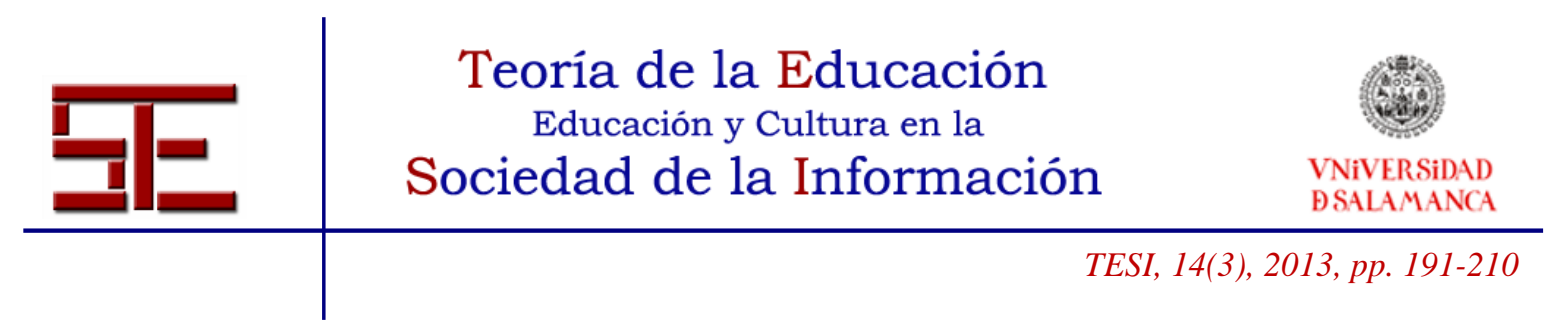

en la memorización y no estimula el cuestionamiento sino la asimilación de conocimientos útiles, en realidad tiene miedo al cultivo y desarrollo de la comprensión porque resulta demasiado peligroso para el crecimiento económico, porque se necesitan personas con una moral obtusa y servidores incondicionales de ninguna ideología.

A consecuencia de ello, los procesos educativos no serían emancipadores o liberadores para las personas que aprenden, sino procesos de instrucción en los que, a juicio de Esteve $(2010,48)$, se cumplen dos condiciones: "el aprendizaje ha desarrollado en la persona [que aprende] esquemas conceptuales... y el alumno ha desarrollado algún tipo de esquema conceptual propio y organiza su información en torno a dicho esquema". Desde estos presupuestos, se piensa que los procesos educativos son básicamente mecanismos de procesamiento de la información, de modo que las actividades de enseñar y aprender pueden ser reducidas a esquemas lógicos. Educar se convierte así en la capacitación para procesar información; es decir, transformar datos o símbolos en resultados prácticos.

Este concepto de educación no compatibiliza bien con la enseñanza de valores ciudadanos y de una cultura compartida que prestigia la diversidad, las diferencias culturales y la convivencia democrática (Souto, 2007). Es más el afán puesto en el crecimiento económico, en la formación de unas destrezas cognitivas básicas (lectoescritura, ciencias, matemáticas e idiomas), y unas aptitudes relacionadas con el emprendimiento, la ciencia, la tecnología, la ingeniería y las matemáticas (Comisión Europea, 2012). En lo profesional se concede más prioridad a la reducción de los déficits en aptitudes relacionadas con el uso de las TIC en sectores básicos (sanidad, servicios, etc.). Así pues, la educación centrada en el crecimiento económico apuesta por la formación en conocimientos, competencias y destrezas cognitivas básicas que están al servicio del mercado laboral.

No es bueno solamente formar personas con conocimientos válidos, con capacidades puestas al día. No es suficiente formar individuos productivos que sean medidos por el beneficio económico y el bienestar material que aportan. Si la formación de la persona solo se limita al dominio de conocimientos científico-técnicos del más alto nivel posible y de las competencias necesarias para su actualización, se corre el riego permanente de que el conocimiento, por sí solo, no sirva para mejorar las condiciones de vida humana de los hombres.

No estamos en contra de que la formación de las personas resulte provechosa para el conjunto de la sociedad, si al mismo tiempo la cultura y la ciencia están al servicio de la promoción humana. Por ello, consideramos importante que la formación genere calidad de vida, entendida ésta como la progresiva humanización del mundo abocada a enfrentarse con problemas de otro orden, que sobrepasan la sola capacitación técnica y profesional. Estamos apuntando pues a otras cuestiones de orden moral que afectan directamente a la relación de cada uno con los demás y con la naturaleza, porque definitiva-

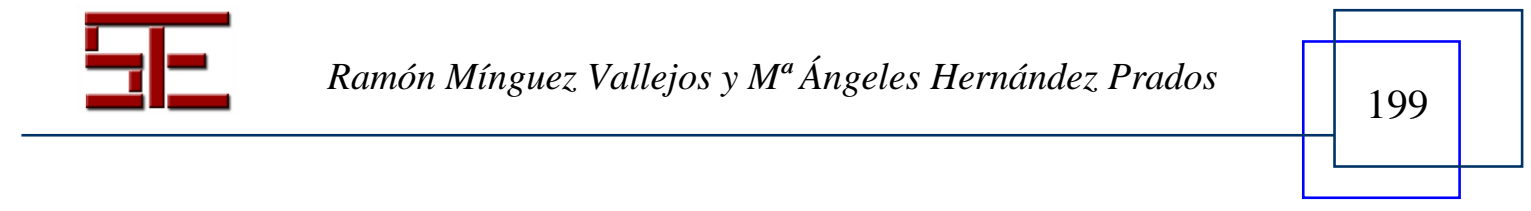




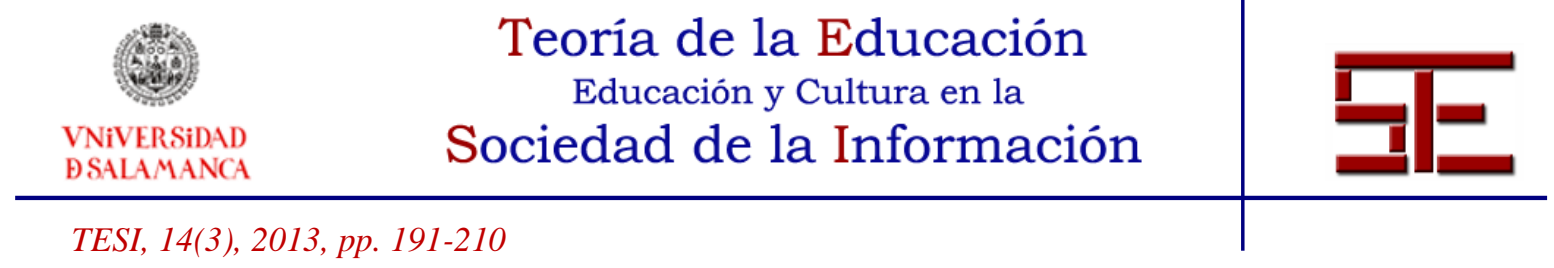

mente nos hacemos humanos cuando nuestras relaciones se fundan "en el interés y el respeto por el otro, que a su vez se fundan en la capacidad de ver a los demás como seres humanos, no como meros objetos" (Nussbaum, 2010, 25). Y en la sociedad del conocimiento, la educación de las personas no debería estar limitada a conocer lo últimamente nuevo, sino más preocupado por los problemas concretos que sufren las personas, porque "el ser humano vuelve a ocupar un lugar esencial en la adquisición y comunicación permanente de los conocimientos" (Bindé 2005, 65).

Quedaría pendiente, pues, poner en marcha unos procesos educativos que eviten una formación despersonalizada, instrumentalizada y al servicio de una cultura individualista. Entonces, expresado en palabras del prof. Esteve $(2010,50)$ "hablar de educación es inseparable de hablar de lo que se considera valioso". En consecuencia, el planteamiento de una concepción humanista de la educación sería como la nueva divisa que debería atender la educación en esta sociedad del conocimiento, tan polarizada en un modelo mecanicista y privado del componente pasional y volitivo de la educación. Se ha educado durante mucho tiempo en una educación centrada en el qué y no en el quién, en los conocimientos que deben ser depositados en "algo" llamado educando, cuando el otro reclama ser acogido de otro modo. Pero esto invita a pensar y hacer otra educación más atenta a la persona y a su realidad concreta.

Desde esa nueva mirada, la educación debería fluir como posibilidad configuradora de unos seres humanos concretos que recorren un determinado trayecto existencial en la búsqueda incesante de dar sentido a sus propias vidas. Con ello queremos hacer una precisión importante: que cada uno de nosotros se hace de modo circunstancial, rodeado de unas condiciones y mediaciones a partir de las cuales la educación aporta -o mejor aún, debería aportar-claves y criterios que le permita comprenderse a sí mismo y comprender todo lo demás para configurarse como persona en una gozosa y saludable relacionalidad humana (Duch, 2004).

\section{EDUCAR DE OTRO MODO EN LA SOCIEDAD DEL CONOCIMIENTO}

Desde el comienzo de la modernidad hasta nuestros días, se ha extendido la tendencia a educar más, casi por completo, en lo efectivo (mentalidad científico-técnica) que en lo afectivo (mentalidad humanista). Y ello ha conducido a una cultura del individualismo (Béjar, 1989). Cultura que ha contribuido al olvido de los unos hacia los otros, a un conjunto de actitudes y comportamientos conforme a una filosofía que reduce las dimensiones personales a rentabilidad y beneficio del interés propio.

Este modus vivendi, tan extendido entre nosotros, ha provocado una significativa incertidumbre en la convivencia que se manifiesta con fenómenos de violencia y de desconfianza. La educación no ha estado ajena a esa realidad, sino que se ha colado en la vida de las aulas y ha impregnado a todos sus elementos. Además, la educación actual se

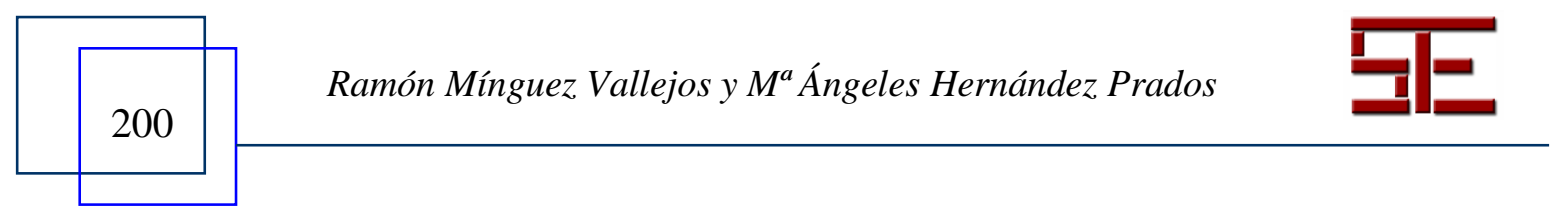




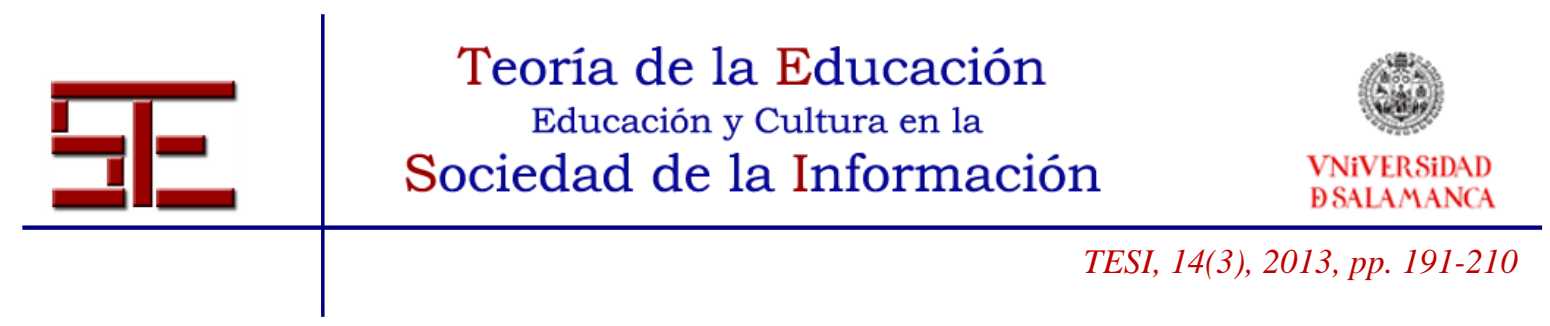

encuentra en una situación en la que está desprovista de teorías que puedan orientar el futuro, por lo que estamos ante una nueva exigencia ética de la educación en la sociedad del conocimiento (Rodríguez de Rávena, 2007).

La propuesta de "educar de otro modo" invita a educar desde otros presupuestos. Nuestra propuesta se centra en la pedagogía de la alteridad (Ortega, 2010). Sustentado en la filosofía de E. Lévinas, esta educación consiste en atender al otro de quien soy responsable y quien me solicita una respuesta. E invita a presentar algunas ideas nuevas, no con la intención de intervenir en los planes de estudios, en la formación de los docentes o en la administración de escuelas y universidades, sino en apelar a la acción personal de hombres y mujeres empeñados por ofrecer una alternativa a los modos deshumanizadores de educar.

Si la educación sirve para aprender a vivir en el mundo, y en él vivimos unos en relación con los otros, la pedagogía de la alteridad es un aprendizaje que se realiza en relación con el otro. Pero, paradójicamente, se ha educado sin hacerse cargo del otro educando, sin atender a su singularidad. En efecto, mucha de la práctica educativa se ha desarrollado en una suerte de educación "indiferente", "a-pática", alejada de lo que acontece en la vida concreta de los educandos. Se ha educado a muchas generaciones en un modelo idealizado de ser humano, modelo que se ha congratulado con el éxito de los derechos humanos como principios reguladores de la vida humana, pero que ha sido incapaz de detener las barbaridades, violaciones e injusticias ocurridas y que siguen aconteciendo en nuestra sociedad "civilizada".

Educar desde la pedagogía de la alteridad significa anteponer al otro, a ese ser concreto en su tiempo y en su espacio. Es la persona sufriente y necesitada de mí lo que importa en última instancia. Es el educando, inmerso en su mundo vital, quien reclama de mi ayuda. Y ello me obliga a dar testimonio de otro modo de educar, distinto y distante de lo que ha sido frecuente hasta ahora en la relación educativa: relaciones basadas en el miedo y preocupados cada uno por sí mismo. "Lo que importa no es lo que hacemos [los maestros] con los estudiantes, sino qué tipo de relaciones construimos con ellos y entre ellos" (Sidorkin, 2007, 108).

Así pues, la relación educativa apropiada en la pedagogía de la alteridad es la acogida del otro-educando en todo lo que es y como es. Desde el momento en que yo-educador acoge la alteridad del otro se convierte en rehén suyo. Y ello obliga a acompañar, prestar atención y ser sensible a la necesidad concreta del otro aún a mi pesar. Es estar dispuesto a responder a la llamada que me llega con las necesidades de los demás educandos, a dar lo que necesita cada otro para educarse.

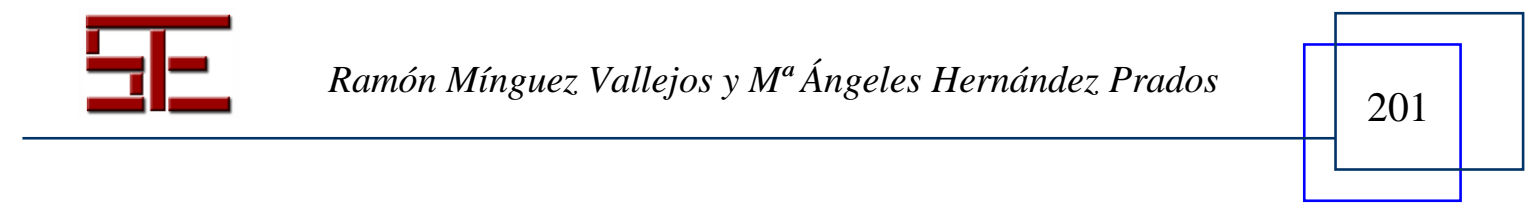




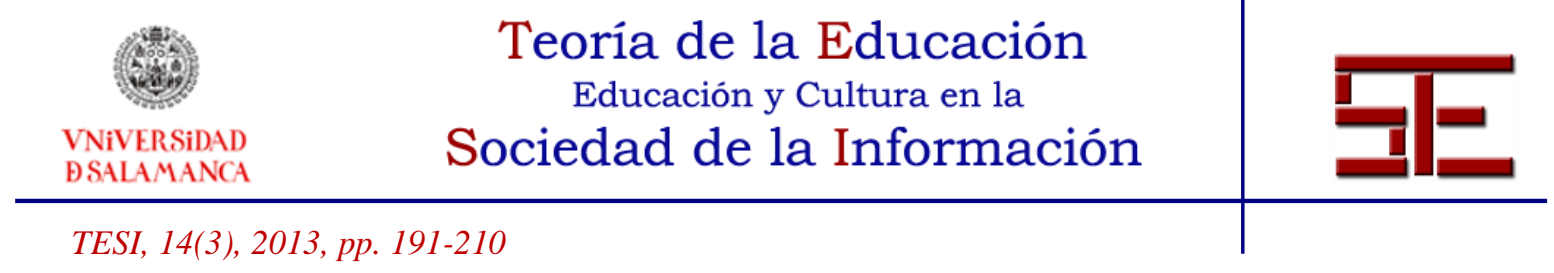

\subsection{La donación en la pedagogía de la alteridad}

En términos generales, el dinamismo de la donación va desde lo que uno es hasta atender aquellas necesidades relacionadas con la vida de las personas. La donación aparece como una alteración de una relación instrumental o calculadora, porque cuestiona las relaciones humanas cosificadas e impide que se convierta en un simple intercambio. En contraposición a una donación interesada, la experiencia y verdad del don está en la obligación de servir a la persona concreta. Por ello, la donación sólo puede pensarse desde la liberalidad, desde la entrega, desde el servicio al que no se le pone condiciones porque desborda la equivalencia entre lo que se da y lo que se recibe (Domingo y Domingo, 2013). En el fondo, la donación es fundamento de la vida moral (Gnada, 2010) $y$, por lo mismo, de la educación moral en clave levinasiana.

Desde la mirada de la donación, educar no consiste en la sola transmisión de conocimientos acerca de lo que el educador sabe o domina. Educar es dar lo que se ha aprendido, es comunicar lo que el educador atesora en su interior y verter al educando el deseo de aprender. A juicio de Torralba (2011), la práctica educativa de la donación se sustenta en tres pilares: la capacidad, el deseo y la esperanza. Es evidente que sin capacidad por ambas partes resulta imposible educar (-se); pero capacidad sin deseo de salir de la ignorancia haría imposible el acto educativo. Más que técnica, la tarea educativa es agápica, expresión de amor incondicional hacia el otro, el deseo del bien del educando. Finalmente, educar es un acto de esperanza, es la creencia de que todo esfuerzo y dedicación tendrá efectos beneficiosos para el educando. En conjunto, educar es dar lo que necesite el educando (conocimientos, saberes, lenguajes, actitudes, etc.) para que sea fecundo su proceso de construcción personal. Además de dar, educar es enseñar al educando a darse a sí mismo. A fin de cuentas, cada cual da lo que es y nadie pueda dar lo que no es.

Bajo esta perspectiva, la educación aparece "como una acción hospitalaria, como la acogida de un recién llegado, de un extranjero" (Bárcena, 2005, 126). Y el educador trata de recibir a este recién llegado, de hacerle como un hueco vital en este mundo para que pueda desarrollarse cabalmente. Por su parte, el educando es como un desconocido, alguien que no es, pero que puede llegar a ser. ¿A qué puede llegar? No se sabe, solo hay incertidumbre sobre quién será. Y ello exige un amplio ejercicio de confianza por parte del educador para que el educando pueda construir su identidad y llegar a ser alguien. También, confianza por parte del educando hacia el educador en cuanto que sabe qué es lo que necesita para educarse.

A este respecto, el educador no debe imponer sus conocimientos, sino debe estar orientado su comportamiento por el afán de decir y hacer la verdad. Se trata de despertar el deseo de conocer, de suscitar el interés por la verdad. No se debe enseñar con la actitud de quien cree saberlo todo o estar en posesión de la verdad absoluta. La verdad no se puede enseñar como si se tuviera todo el poder. Es preferible enseñarla de modo cálido,

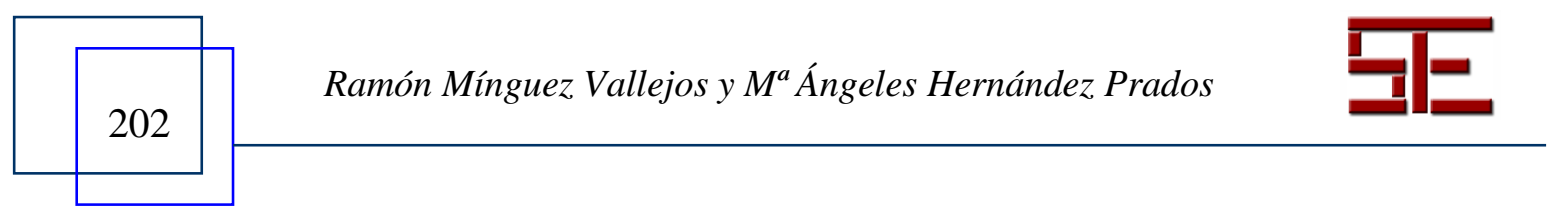




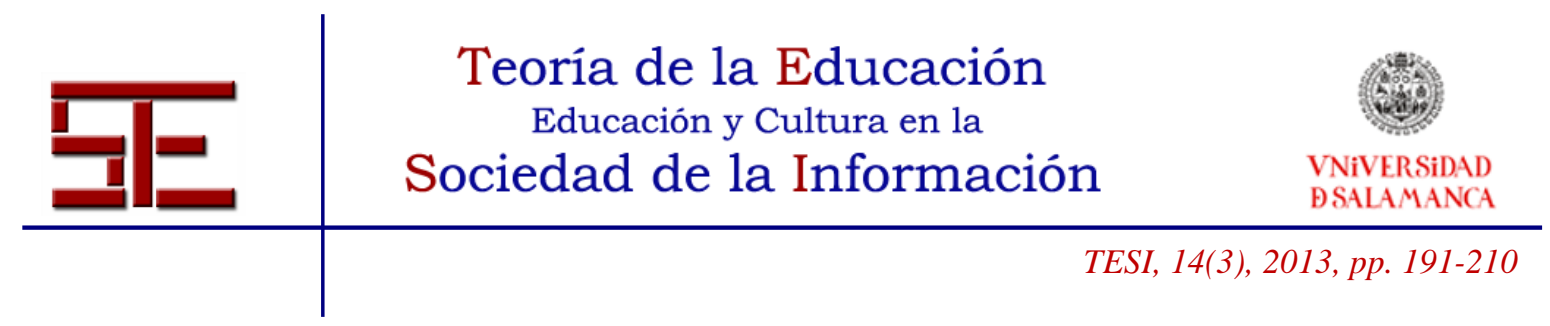

como si fuera una invitación a saber. Y puede ocurrir que algún educando pregunte: "¿Para qué saber más? Seguramente la mejor respuesta que pueda darse sea ésta: para conocer mejor quienes somos, para poder decidir con más libertad y responsabilidad lo que yo quiero hacer en mi vida, para saber explicar y dar cuenta de todo aquello que está ocurriendo en mi entorno y en el mundo, para poder disfrutar más de lo que existe, para ser más como humano en definitiva" (Ortega y Mínguez, 2001, 114). El conjunto de conocimientos y de actitudes en la búsqueda del saber y de apertura a lo desconocido, debe ser el impulso a meterse en una cultura que le servirá al educando como para estar protegido y sentirse a gusto. Y para que esto sea algo verosímil, es necesario un nuevo estilo de relación interpersonal entre educador-educando.

\subsection{Estilo educativo de la pedagogía de la alteridad}

A nuestro juicio, ese nuevo estilo de relación está orientado por dos actitudes básicas: la acogida del otro concreto y el diálogo que se entabla con él. Acoger y dialogar comportan una relación interpersonal valiosa, "es esta disposición de apertura al otro, de abandono y renuncia de sí mismo lo que hace que el otro me importe, me descentre para ponerme en el lugar del otro. Sólo así el maestro educa" (Gárate y Ortega, 2013, 149). De este modo, educar no acaba en procurar un buen ropaje intelectual, sino también en el aprendizaje de un conjunto de valores claves para que el educando llegue a estar bien equipado en su vida como persona. Por ello, resulta decisivo que las escuelas y las aulas se conviertan en espacios de aprendizaje moral, expresión del respeto, de la confianza, de la responsabilidad y la esperanza. Sin un ethos, un clima moral presente en la vida de las aulas, será muy difícil que se llegue a educar moralmente.

Ese clima moral reclama un estilo dialogante, siempre dispuesto al encuentro, a la escucha y al entendimiento recíproco. El diálogo no solo es una plática o conversación entre, al menos, dos interlocutores. Además, presenta algunas exigencias. Siendo la actitud de respeto y búsqueda de la verdad una de ellas, es importante que el diálogo sea un espacio de encuentro con el otro a través de la palabra, del gesto y de la presencia. Es como un ir más allá de lo que se dice y descubrir lo que cada uno es. Por ello, consideramos que el educador debe practicar la escucha activa entendida como "el arte de cargar, de acoger la experiencia ajena, personal y misteriosa, sobre las propias espaldas" (Bermejo y Martínez, 2012, 52).

Escuchar a cada educando es exigencia que no puede eludir el educador, porque lo más difícil en el diálogo es siempre escuchar a alguien que no sea 'yo mismo'. Aceptar la existencia de otro distinto de mí requiere una atención exclusiva. La escucha del otro es obedecer (del latín ob audire, escuchar al que está enfrente de mí, oír atentamente), es practicar esa atención que me obliga a entregarme a una tarea diferente y siempre nueva. No se trata de que el educador piense en lo que tiene que hacer o dejar de hacer con

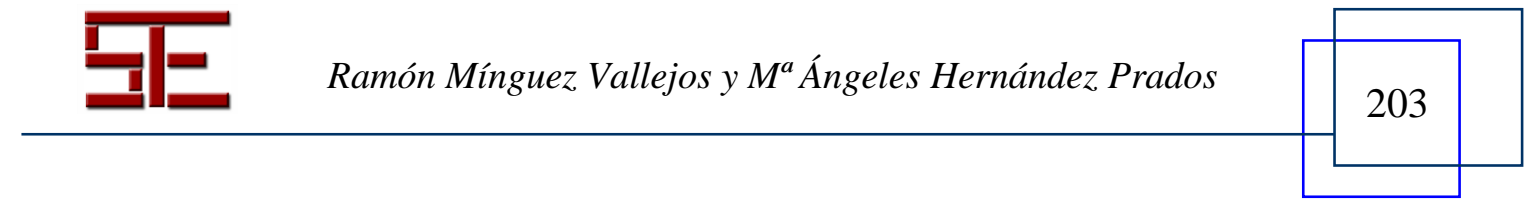




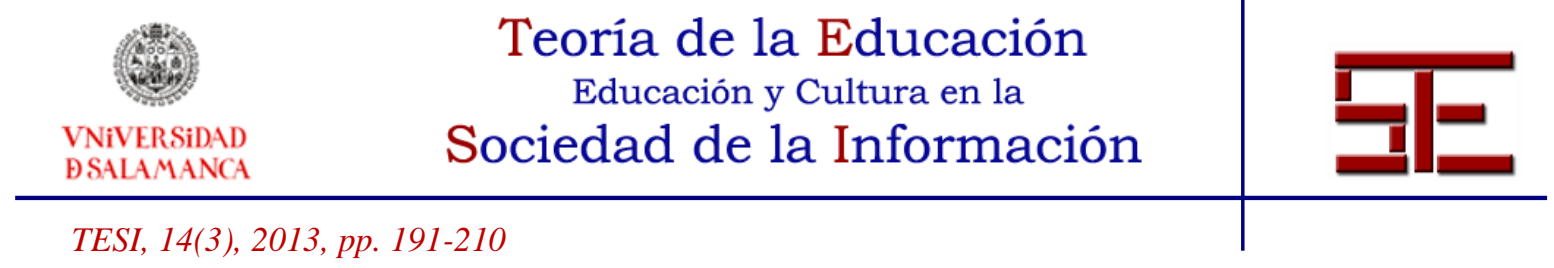

cada educando y en cada situación educativa, sino más bien de pensar en para quién hace lo que hace. A fin de cuentas, el educador debe estar impulsado por un sentimiento de ayuda ilimitada al educando, a ese en concreto.

La práctica de la escucha activa presenta algunas ventajas en la relación educativa: al sentirse escuchado, el educando expresará la confianza necesaria para ser sincero con el educador y con quienes le rodean; si es valorada su persona entre los interlocutores, se favorece una relación positiva y un clima tranquilizante que contribuye a eliminar tensiones innecesarias; al practicar la escucha activa, es posible profundizar en los problemas y tomar decisiones no apresuradas. Este modo de escuchar es una de las necesidades más sentidas en una sociedad tan autista o individualista como la actual. Del diálogo fundado en la escucha atenta y la palabra acogedora dependerá que las personas sean capaces de expresarse y concretar las experiencias que le humanizan.

Educar así nos aleja de una visión universalista de la educación desde la que han sido formadas muchas generaciones. También nos separa de una educación que deriva de un deber abstracto, como si educar se ajustase al cumplimiento de unos principios y reglas que regulan la actividad del educador. Y nos desmarca de ver al educando como un objeto, como si fuera un simple depositario de saberes, en la pretensión de controlar las principales variables que intervienen en la adquisición de conocimientos y habilidades que garantizan el éxito de la tarea educadora.

La educación que emana de la pedagogía de la alteridad es ética. Parte del supuesto de que educar es hacerse cargo del otro en su fragilidad, de responder al otro concreto como ser vulnerable. Ello implica la práctica de la compasión, del otro necesitado de mi ayuda, en cuanto camino de reconocimiento de la alteridad y relación con los otros.

\subsection{El aprendizaje de la compasión}

No resulta fácil el aprendizaje de la compasión. ¿Es posible aprender a compadecer? Con bastante frecuencia se hace discurso o se señalan conductas como formas de expresar la compasión. Sin embargo, no se deja escuchar el componente de pasión y percibir la reacción apasionada de personas ante situaciones de injusticia, como tampoco la demanda de justicia.

La compasión se convertiría en una caricatura, si ella quedase reducida a la sola comprensión intelectual sobre el sufrimiento injusto de millones de seres humanos. Por ello, llevando este argumento a la práctica educativa, deducimos que no se puede aprender a compadecer si da lugar sólo a la explicación de la misma. Mientras que explicar la compasión se mueve en el terreno de la lógica y del discurso, el sentimiento compasivo que da acceso al sujeto compasivo solo ocurre si hay experiencia. Conviene no confundir el aprendizaje de la experiencia con el de las explicaciones. Uno es el de instruir y explicar; el otro es de acoger y responder. Visto así, compadecer es acompañar y respetar, es

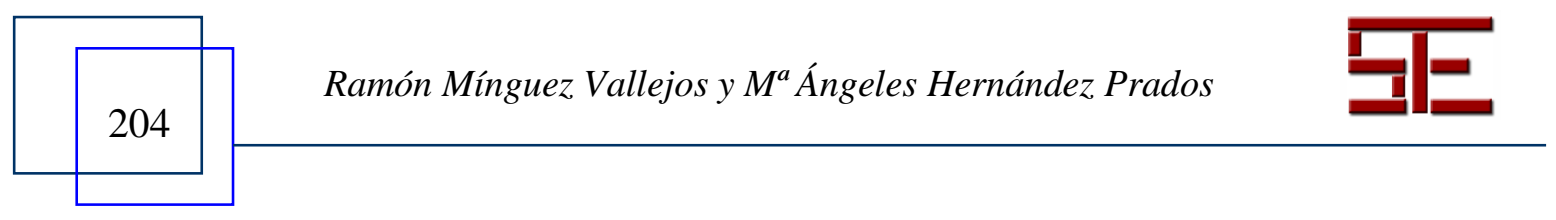




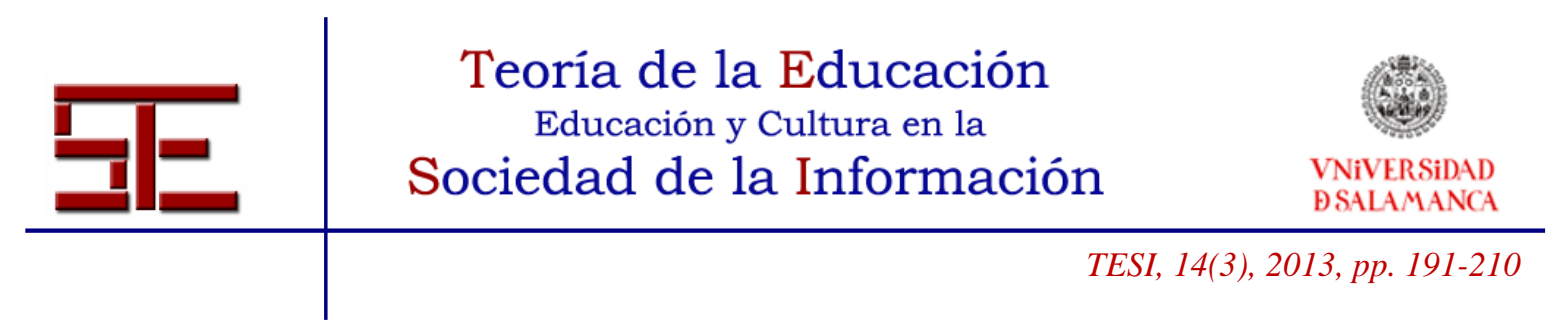

estar ahí extendiendo mi mano a otro para dar de mí en cada momento. Es el afecto y la relación personal lo que da acceso a la ayuda compasiva.

El aprendizaje de la compasión se expresa en la respuesta-responsable que yo doy al otro sufriente. De ahí que la praxis educativa de la compasión siempre está atrapada en la circunstancia concreta del educando. Y esa praxis nunca podrá llegar a ser una acción de validez universal porque se resuelve en la circunstancia concreta del educando.

Ahora bien, la vida cotidiana del aula pone a la vista situaciones que pueden ser motivo de acceso a la experiencia de la compasión. Y ello resulta bastante evidente cuando se constata la presencia de sujetos que sufren alguna discapacidad física o mental, bien sea de carácter hereditario o a consecuencia de alguna enfermedad sobrevenida. De igual modo, el maltrato entre iguales, entre profesor-alumno y de alumnos hacia el profesor, reflejan estados sufrientes en los que el otro es subyugado y enajenado de su persona. Otras situaciones como la xenofobia, la violencia de género, el sufrimiento de inocentes, el maltrato infantil, la exclusión y marginación social, son manifestaciones de situaciones injustas que sirven de acceso a la compasión. Sin embargo, no comienza realmente el aprendizaje de la compasión sin el sentimiento que me une a la suerte del otro concreto como ser doliente que me demanda una respuesta-responsable.

¿Qué respuesta dar ante el sufrimiento del otro y su realidad concreta? Habitualmente hay derroteros de la compasión que discurren por sentimientos de conmiseración, lástima o piedad hacia el otro necesitado. Nuestra conciencia nos induce a saldar una deuda para con el otro. Y esta conciencia se traduce en tareas de dar cuenta no sólo de lo que hacemos, sino de aquellas por las que nos hacemos responsable de ellos, que comprende el afecto, el cuidado y el tacto. Estos derroteros no son exactamente equiparables a la respuesta ética que aquí estamos proponiendo. Nos distanciamos de las teorías morales del cuidado (Katz, Noddings y Strike, 2002) y de las propuestas formativas del cuidado (Vázquez, Escámez y García, 2012). De igual modo, la pedagogía de la alteridad no es la pedagogía de la emoción (Bisquerra, 2008) o del tacto afectivo (Manen, 1998). Estas pedagogías reducen la práctica educativa a una cuestión de afecto, de emoción que mueve a la persona hacia el cuidado, la atención y el tacto sensible con el otro; sin embargo, evitan una acción que no sea una afirmación radical del otro.

La pedagogía de la alteridad trata de acoger con las propias entrañas la situación del otro, de compartir el sufrimiento del otro (cum-pati = padecer con). No debe confundirse con un sentimiento de lástima que se sabe lejos de la situación del que sufre, sino apostar por lo inmediatamente sentido a causa de la carencia, la privación y la necesidad del otro en su situación concreta (Ortega y Mínguez, 2007). Por eso, el camino de la compasión es acercarse al otro, arriesgarse y exponerse, no dar un rodeo o elaborar un discurso sobre las causas de su sufrimiento, su incomunicación o su sentimiento de soledad. La acción de hospedar al otro rompe con el trato impersonal e impone la lógica de la cordialidad. En el terreno educativo, supone anteponer la persona concreta a las

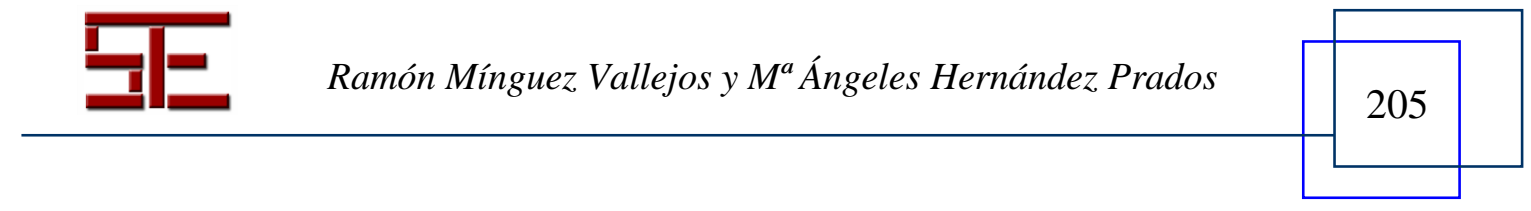




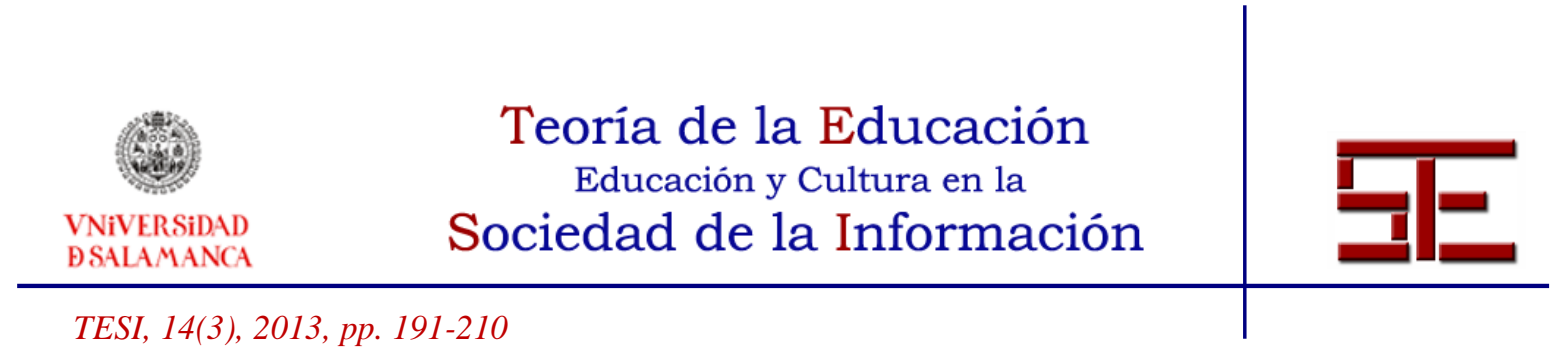

propias ideas u opiniones para escuchar las del otro (Mínguez, 2010). Además, se sustenta en la confianza en el ser humano y en la posibilidad de salir de sí mismo para dar lugar al nacimiento de una nueva vida para ambos.

Además, educar de modo compasivo es educar en la solidaridad y la justicia social. Y para ello no basta con acciones asistenciales, sino también comprometidas con el desarrollo de personas y pueblos. Nos situamos en una tarea educativa más vinculada a lo que Martha Nussbaum define como el enfoque de las capacidades. La pregunta clave que emana de ahí es: “¿qué es capaz de hacer y de ser cada persona?” (Nussbaum, 2012, 38). Y esa pregunta lleva a centrar la atención en las oportunidades que dispone cada individuo para desarrollarse como ser humano. Se trata de un enfoque centrado en las capacidades que son valiosas para el desarrollo humano y, además, en las oportunidades que se disponen para elegir y actuar posteriormente en la situación política, social y económica. Desde esa perspectiva, educar significa el equipamiento de unas capacidades humanas en interacción con su entorno familiar, social y político.

Educar en capacidades es promover una educación que responda a las principales necesidades para un adecuado desarrollo humano, una educación que logre disminuir la pobreza física (poder vivir con buena salud, recibir una alimentación adecuada, disponer de un hogar apropiado y sentirse protegido física y moralmente); una educación comprometida con la erradicación de la pobreza cultural (que incluya la alfabetización y el uso del pensamiento y de la imaginación con garantías de libertad política y religiosa); una educación que desarrolle la dimensión social-relacional de la persona y así evite su soledad, su incomunicación, discriminación o marginación. Una educación, a fin de cuentas, que contribuya a la integración de las personas en una sociedad plural, justa, solidaria y pacífica.

\section{A MODO DE REFLEXIÓN FINAL}

No puede lograrse otro modo de educar si no se materializan respuestas concretas a esos seres humanos que, con su presencia, nos lanzan una pregunta: ¿Qué hay de lo mío para ser humano? Y la historia reciente nos aporta algunos ejemplos de hacerse cargo del otro. Sirva como muestra el testimonio de los goyims como un modo de arriesgar la propia vida por salvar a extraños del horror nazi, a perder todo cuanto les era cercano y querido a favor de desconocidos, sin estar obligados a hacerlo. O también el comportamiento valeroso de unos jóvenes, el grupo de la Rosa Blanca, que no quisieron ser cómplices de la barbarie y se sintieron culpables si no se solidarizaban con las víctimas.

Hoy es urgente hacer justicia social y ser solidario con las necesidades de desarrollo de las personas. Y ello implica un estilo educativo que ponga como centro al otro necesitado de mi ayuda. Educar en vistas al crecimiento económico sería tomar al otro como un

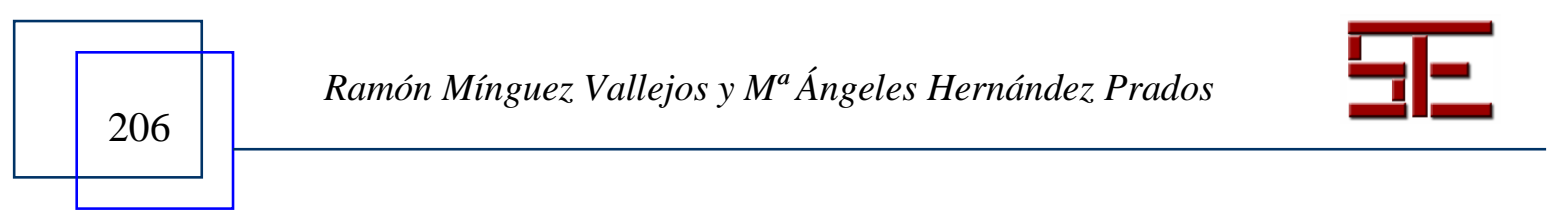




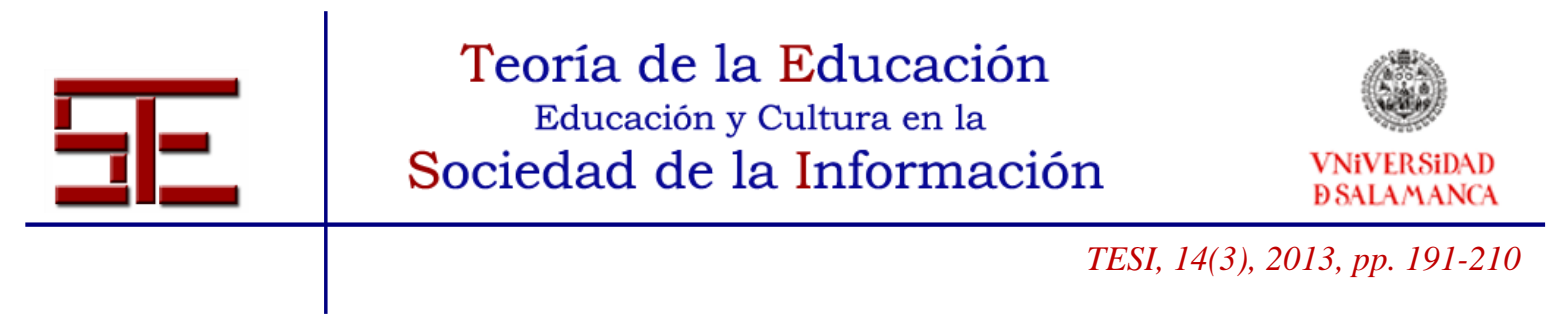

instrumento al servicio de otros intereses, ajenos a la vida humana misma. En cambio, aquí proponemos adoptar la perspectiva de que el educando es alguien que me demanda una respuesta concreta y a quien me debo aún a mi pesar. Esta perspectiva, hasta ahora poco frecuente, nos aleja de un modelo ideal de educación, tan bello como abstracto que dejaría inmune a muchos educandos que están oprimidos y sufren injusticias. Esa educación es exigencia y esperanza de recobrar una justicia y una educación que sea responsable de la suerte del otro (Ortega y Romero, 2013). Al querer educar así hay una pregunta que se hace inevitable: ¿quién es el educando para mí? ¿Qué relación establezco con él? Solo en la medida en que sea reconocido como alguien, habrá posibilidad de educar.

\section{REFERENCIAS}

Alighieri, D. (1995). El convite. Barcelona: Círculo de Lectores.

Aramayo, R. R. (2001). Kant y la Ilustración. Isegoría, 25, 293-309.

Bárcena, F. (2005). La experiencia reflexiva en educación. Barcelona: Paidós.

Bauman, Z. (2006). Vida líquida. Barcelona: Paidós.

Bauman, Z. (2012). Sobre la educación en un mundo líquido. Barcelona: Paidós.

Béjar, H. (1989). La cultura del individualismo. Revista Española de Investigaciones Sociológicas, 46, 51-80.

Bermejo, J. C. y Martínez, A. (2012). Humanizar el liderazgo. Bilbao: DDB.

Bindé, J. (2005). Hacia las sociedades del conocimiento. París: UNESCO.

Bisquerra, R. (2008). Educación emocional y bienestar. Barcelona: Wolters Kruwer Espña.

Carracedo, J. (2009). Ética para el siglo XXI. Barcelona: Proteus.

Chillón, A. (2010). La condición ambigua. Diálogos con Lluis Duch. Barcelona: Herder.

Comisión Europea (2004). Competencias clave para un aprendizaje a lo largo de la vida. Un marco de referencia europeo. Bruselas: Dirección General de Educación y Cultura.

Comisión Europea (2007). Competencias clave para un aprendizaje permanente. Un marco de referencia europeo. Bruselas: Dirección General de Educación y Cultura.

Comisión Europea (2012). Un nuevo concepto de educación: invertir en las competencias para lograr mejores resultados socioeconómicos. Estrasburgo: Comisión Eu-

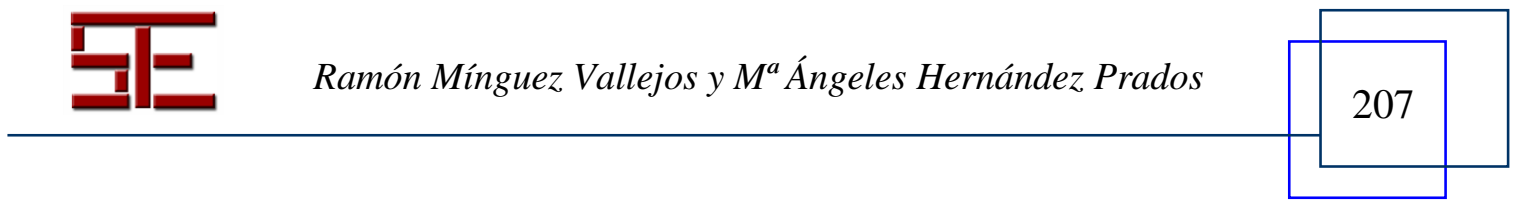




\section{Teoria de la Educación \\ Educación y Cultura en la \\ VNiVERSIDAD \\ DSALAMANCA \\ Sociedad de la Información}

TESI, 14(3), 2013, pp. 191-210

ropea. Extraído el 24 de julio de 2013 de http://ec.europa.eu/education/news/rethinking/com669_es.pdf.

Domingo, A. y Domingo, T. (2013). Filosofías del don. Usos y abusos de la donación en la ética contemporánea. Veritas, 28, 41-62

Drèze, J. y Sen, A. (2002). India: Development and Participation. New York: Oxford University Press.

Duch, L. (2004). Estaciones del laberinto. Ensayos de antropología. Barcelona: Herder.

Esteve, J. M. (2010). Educar: un compromiso con la memoria. Barcelona: Octaedro.

Eurydice (2002). Las competencias clave. Un concepto en expansión dentro de la educación obligatoria. Madrid: Eurydice, Unidad Española.

Gárate, A. y Ortega, P. (2013). Educar desde la precariedad. La otra educación posible. Mexicali: Ediciones Cetys.

Gargallo, B. (2012). Un aprendiz estratégico para una nueva sociedad. Teoría de la Educación. Educación y Cultura en la Sociedad de la Información, 13 (2), 246272.

Gevaert, J. (2008). El problema del hombre. Introducción a la antropología filosófica. Salamanca: Sígueme.

Gnada, A. (2010). El don como principio del actuar moral. Moralia. Revista de Ciencias Morales, 33, 409-427.

Jonnaert, P. (2002). Compétences et socioconstructivisme: Un cadre théorique. Bruxelles: De Boeck \& Larcier.

Katz, M. S.; Noddings, N. y Strike, K. A. (2002). Justicia y cuidado. Barcelona: Idea books.

López Rupérez, F. (2012). La escuela que necesitamos también en España. En E. D. Hirsch. La escuela que necesitamos (pp. 21-30). Madrid: Encuentro.

Manen, V. (1998). El tacto en la enseñanza. Barcelona: Paidós.

Martínez, F. y Gutiérrez, I. (2011). Impacto social, cultural y educativo de las TIC en la sociedad del conocimiento. En F. Martínez e I. Solano (coords.). Comunicación y relaciones sociales de los jóvenes en la red (pp. 13-25). Alcoy: Marfil.

Mínguez, R. (2010). La escuela en la encrucijada. Hacia otra educación desde la ética de E. Lévinas. Teoría de la Educación. Revista Interuniversitaria, 22 (2), 43-61.

Nussbaum, M. C. (2010). Sin fines de lucro. Por qué la democracia necesita de las humanidades. Buenos Aires: Katz.

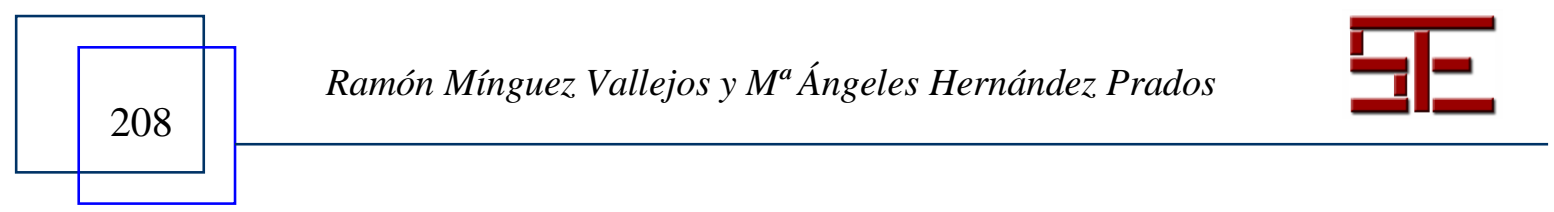




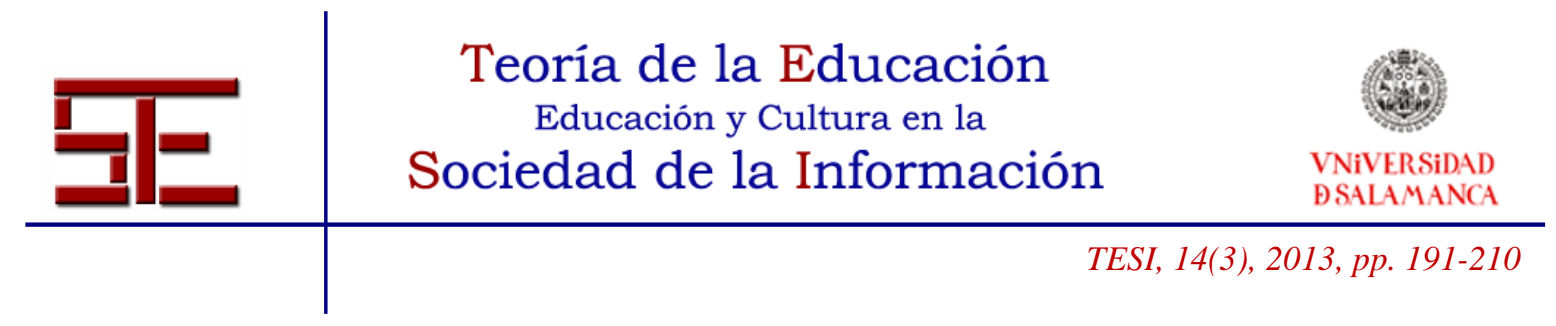

Nussbaum, M. C. (2012). Crear capacidades. Propuesta para el desarrollo humano. Barcelona: Paidós.

Ortega, P. (2010). Educar es responder a la pregunta del otro. Edetania. Estudios y propuestas socio-educativas, 37, 13-31.

Ortega, P. y Mínguez, R. (2001). Los valores en la educación. Barcelona: Ariel.

Ortega, P. y Mínguez, R. (2007). La compasión en la moral de A. Schopenhauer: implicaciones educativas. Teoría de la Educación. Revista Interuniversitaria, 19, 117 137.

Ortega, P. y Romero, E. (2013). La experiencia de las víctimas en el discurso pedagógico. Teoría de la Educación. Revista Interuniversitaria, 25 (1), 63-77.

Pozo, I. (2005). Aprendices y Maestros. La nueva cultura del aprendizaje. Madrid: Alianza Editorial.

Rodríguez de Rávena, R. (2007). La escuela y las nuevas exigencias éticas de la sociedad del conocimiento. En M. Fernández, X. M. Souto y R. Rodríguez. La sociedad del conocimiento: democracia y cultura (pp. 103-149). Madrid: MECOctaedro.

Ruiz de la Peña, J. L. (1994). ¿Homo cyberneticus? Antropología e Inteligencia artificial. En J. de Sahagún Lucas (dir.). Nuevas antropologías del siglo XX (pp. 79112). Salamanca: Sígueme.

Sidorkin, A. M. (2007). Las relaciones educativas. Educación impura, escuelas desescolarizadas y diálogo con el mal. Barcelona: Octaedro.

Souto, X. M. (2007). Cultura académica, diversidad social y fracaso escolar. En M. Fernández, X. M. Souto y R. Rodríguez. La sociedad del conocimiento: democracia y cultura (pp. 39-102). Madrid: MEC-Octaedro.

Torralba, F. (2011). La lógica don. Madrid: Khaf.

Vázquez, V.; Escámez, J. y García, R. (2012). Educación para el cuidado. Hacia una nueva pedagogía. Valencia: Edt. Brief.

Zamora, J. A. (2011). La cultura del consumo: El universo encantado de la mercancía. Éxodo, 111, 20-30.

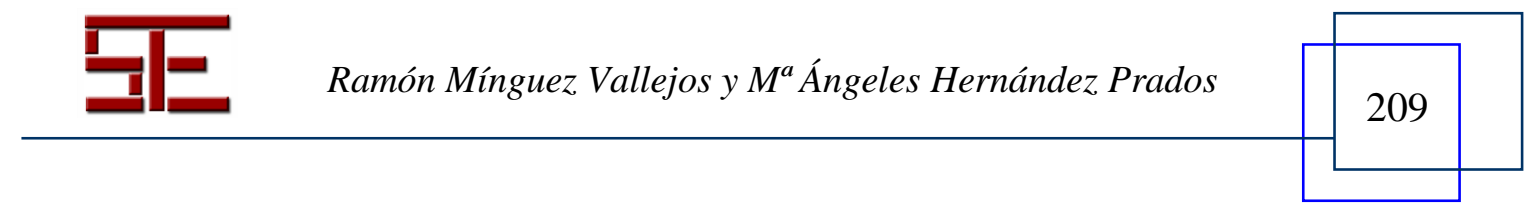




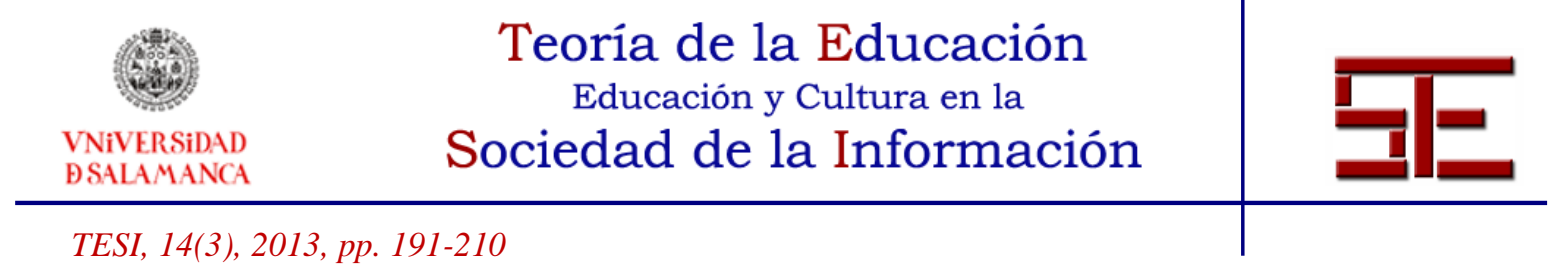

Para citar el presente artículo puede utilizar la siguiente referencia:

Mínguez Vallejos, R. y Hernández Prados, M. A. (2013). Hacia otra educación en la sociedad del conocimiento: cuestiones y propuestas pedagógicas. Revista Teoría de la Educación: Educación y Cultura en la Sociedad de la Información. 14(3), 191-209 [Fecha de consulta: $\mathrm{dd} / \mathrm{mm} / \mathrm{aaa}]$.

http://campus.usal.es/ revistas_trabajo/index.php/revistatesi/article/view/11357/11774

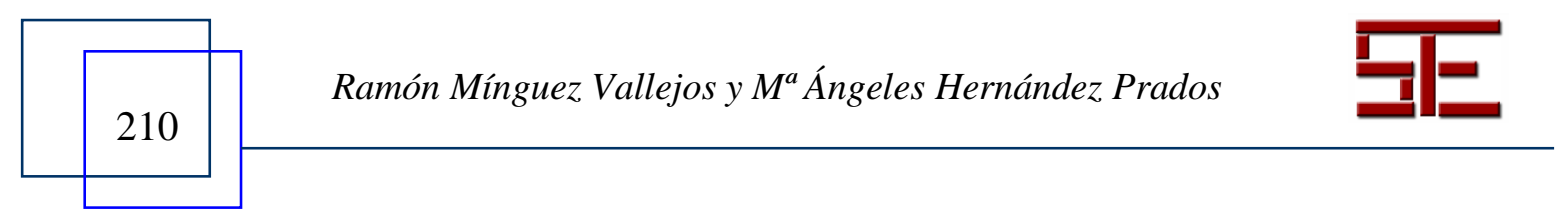

